\title{
ZEBRAFISH IRRITANT RESPONSES TO WILDLAND FIRE-RELATED BIOMASS SMOKE ARE INFLUENCED BY FUEL TYPE, COMBUSTION PHASE, AND BYPRODUCT CHEMISTRY
}

\author{
William Kyle Martin
}

A thesis submitted to the faculty of the University of North Carolina at Chapel Hill in partial fulfillment of the requirements for the degree of Master of Science in the Curriculum in Toxicology and Environmental Medicine in the School of Medicine.

Chapel Hill

2021

Approved by:

Rebecca Fry

Ilona Jaspers

Aimen Farraj 
(C) 2021

William Kyle Martin

ALL RIGHTS RESERVED 


\begin{abstract}
William Kyle Martin: Zebrafish irritant responses to wildland fire-related biomass smoke are influenced by fuel type, combustion phase, and byproduct chemistry

(Under the direction of Aimen Farraj)
\end{abstract}

Wildfire-derived particulate matter (PM) is linked to poor health; however, little is known regarding the influence of fuel type and burn conditions on toxicity. The irritant potential of extractable-organic-material (EOM) of smoke from five fuels (Eucalyptus, Pine, Pine Needle, Peat, or Red Oak), burned at two temperatures each (flaming $500^{\circ} \mathrm{C}$; smoldering $640^{\circ} \mathrm{C}$ ) was assessed using a locomotor assay in zebrafish. It was postulated that locomotor responses might depend up on fuel type and burn conditions, driven by combustion-byproduct chemistry. Locomotor activity was tracked for 60-min in 6-day-old-zebrafish ( $n=25-32)$ immediately after exposure to vehicle or EOM $(0.3-30 \mu \mathrm{g} / \mathrm{ml})$. On a $\mu \mathrm{g}$-EOM-basis, flaming pine and eucalyptus were the most irritating. However, based on EOM-produced/kg-of-fuel-burned, smoldering condensates induced greater irritation than flaming, with smoldering pine being most potent. Irritant responses correlated significantly with polycyclic aromatic hydrocarbons content. Fuel type and burn condition influence the quantity and chemical composition of PM and toxicity. 
I would like to thank my family: my mother, my siblings, and my dog.

I would like to thank my friends, who are family.

More than anyone, I would like to thank Aimen, my mentor. There was never a moment I felt that I could not turn to you for advice on any challenge that faced me.

This work is dedicated to those whose lives science aims to improve. 


\section{ACKNOWLEDGEMENTS}

The work presented here is the product of contributions by many great scientists. I wish

to thank Dr. Stephanie Padilla for invaluable guidance to this project and to my education as a scientist. I would like to thank all members, present and past, of the labs of Drs. Aimen Farraj, Mehdi Hazari, Stephanie Padilla, Ian Gilmour, and Michael Hays who assisted in project design and execution. Furthermore, this work was supported by all members of the Cardio-Pulmonaryand Immuno- Toxicology Branch of the US EPA. I would like to thank the UNC Curriculum in Toxicology and Environmental Medicine and acknowledge the funding they provided me in the form of our departmental T32 (National Research Service Award T32 ES007126, NIEHS). Finally, I would like to thank my patient committee members: Rebecca Fry and Ilona Jaspers. 


\section{TABLE OF CONTENTS}

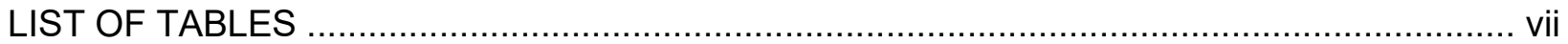

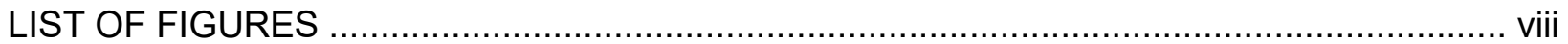

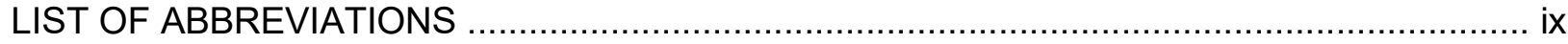

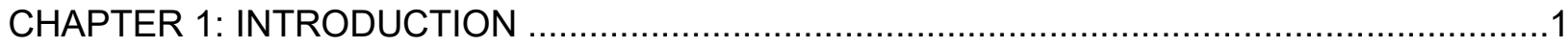

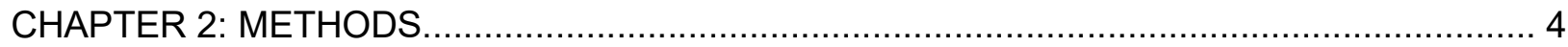

Combustion and byproduct collection.......................................................................

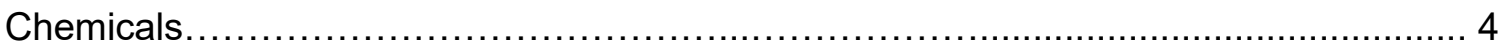

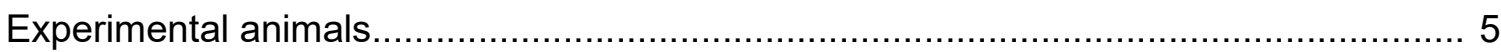

Group size determinations and controlling for plate variability..................................... 5

Concentration-response studies...........................................................................

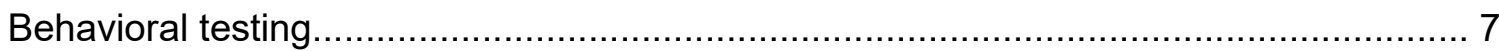

Correlations of potency vs. chemical constituents.................................................... 9

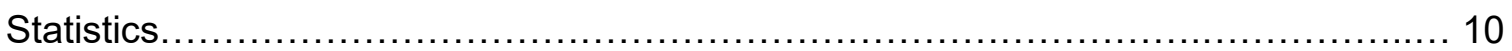

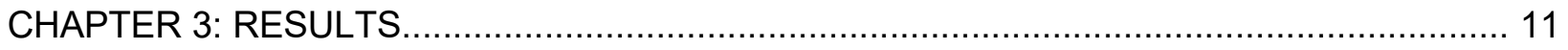

Time course of locomotor responses to extracts.................................................... 11

Potency determinations for extracts................................................................. 15

Correlations of potency with chemical constituents................................................. 17

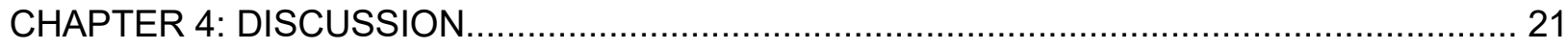

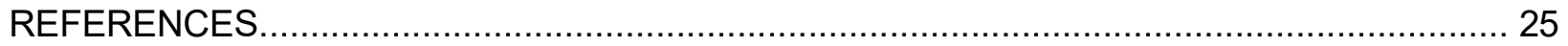




\section{LIST OF TABLES}

Table

1. Concentrations of chemicals in the biomass smoke condensates in $\mathrm{mg} / \mathrm{g} \mathrm{PM} \ldots \ldots \ldots . . .9$

2: Concentrations of chemicals in the biomass smoke condensates in $\mathrm{g} / \mathrm{kg}$ fuel..........9 


\section{LIST OF FIGURES}

Figure 1. Experimental protocol for treatment and behavior assessment of zebrafish larvae.... 8

Figure 2: Effect of smoldering EOM samples on zebrafish larval locomotor activity measured in dark over the course of a 60 -min monitoring period.... 12

Figure 3: Effect of flaming EOM samples on zebrafish larval locomotor activity measured in the dark over the course of a 60 -min monitoring period....

Figure 4: Potency of all extracts on an extractable organic material (EOM) basis in the zebrafish locomotor assay.

Figure 5: Potency of all extracts on an emission factor (EF) basis in the zebrafish locomotor assay. 17

Figure 6: Correlations between irritant potencies in zebrafish and concentration of specific chemical classes on an extractable organic material (EOM) mass basis..... 18

Figure 7: Correlations between irritant potencies in zebrafish and concentration of specific chemical classes on an emission factor (EF) basis. 


\section{LIST OF ABBREVIATIONS}

\begin{tabular}{ll} 
DMSO & \multicolumn{1}{l}{ Dimethyl Sulfoxide } \\
DPF & Days-post-fertilization \\
EF & Emission factor \\
EOM & Extractable organic material \\
HBSS & Hanks' Buffered Saline Solution \\
MCE & Modified combustion efficiency \\
PAH & Polycyclic aromatic hydrocarbons \\
PM & Particulate matter \\
TRP & Transient Receptor Potential
\end{tabular}




\section{CHAPTER 1: INTRODUCTION}

The warming and drying trends associated with climate change are lengthening wildland fire season, expanding the geographical areas that are fire prone, and intensifying fires (Jolly et al., 2015; Burke et al., 2019; Westerling et al., 2006; Trenberth, 2011). One consequence of these trends is an increase in quantities of local and global fine particulate matter $\left(\mathrm{PM}_{2.5}\right)$, a respirable mixture less than $2.5 \mu \mathrm{m}$ in aerodynamic diameter consisting of black carbon, organics, and/or metals (Urbanski, 2013). Inhalation of $\mathrm{PM}_{2.5}$ has for decades been demonstrated to produce and/or exaggerate adverse health outcomes such as pulmonary distress and cardiovascular diseases (Lim et al., 2012; Wettstein et al., 2018; Samet et al., 2009; Cochard et al 2020; Shkirkova et al 2020). Further, human and experimental evidence indicates that the severity of adverse health effects is influenced heavily by air pollution source (Hime et al., 2018; Park et al., 2018). This includes studies that have demonstrated enhanced toxicity of combustion emissions from petroleum diesel relative to biodiesel (Shvedova et al 2013; Mutlu et al., 2015; Hazari et al., 2015; Farraj et al., 2015; Gavett et al., 2015), of metalrich residual oil-fly ash relative to carbon black (Wellenius et al., 2002), and of near road PM relative to rural PM (Hargrove et al,. 2018). However, little progress has been made in identifying differences in adverse health effects that may exist due to the unique biomass composition of one vegetated area versus another and the respective resultant composition of the $\mathrm{PM}_{2.5}$ generated when wildlands burn. For example, the increasingly severe Western U.S.A. wildfires, which burn evergreens and, specific to the west coast, eucalyptus, may produce smoke of different chemical composition than the peat bogs of the southeastern U.S.A (Urbanski et al., 2008). 
Rodent models have long been the canonical experimental model system for the investigation of adverse health impacts of respirable pollutants including biomass combustion emissions (Martin et al., 2020). However, rodent inhalation exposure studies are limited by the time and expense needed to acquire and process toxicity information. As an alternative animal model for biomedical research, including toxicology, the zebrafish has seen a meteoric rise to prominence driven by the high degree of conservation of the genome, genomic synteny, and analogous expression of proteins involved in human disease, which is $>80 \%$ (Gunnarsson et al. 2008; Howe et al., 2014). Zebrafish have high fecundity, are amenable to genetic and pharmacological manipulation, have low maintenance costs and share key similarities to human physiology. Importantly, zebrafish skin epithelium is sensitive to many chemicals that irritate lung epithelium in mammals (Kroll et al. 2021; Prober et al., 2008) and expresses the same chemical sensors that are expressed in the mammalian lung including the transient receptor potential (TRP) cation channel TRPA1. Activation of such channels, which mediate chemosensation to a variety of xenobiotics (Prober et al. 2008) and pro-oxidants (Takahashi et al. 2011), enhances locomotor activity in zebrafish, responses that can be easily measured, and were used previously as a readout of the irritant potential of diesel exhaust $\mathrm{PM}_{2.5}$ (Stevens et al., 2018). Furthermore, locomotor responses have been used previously as a measure of the potency of the irritant, including responses to the well-known human irritants mustard oil, cinnamon oil and acrolein (Prober et al. 2008).

The main objective of this study was to use a zebrafish locomotor assay to (1) screen the irritant potential of $\mathrm{PM}_{2.5}$ from combustions emissions of key wildland-fire related biomass sources and (2) relate biological responses to combustion conditions and chemical composition. To do so, five fuel sources (pine, pine needle, red oak, peat, and eucalyptus), each representing a different major wildland fuel type in the USA, were each burned at two separate combustion temperatures, smoldering (approximately $500^{\circ} \mathrm{C}$ ) and flaming (approximately $640^{\circ} \mathrm{C}$ ), representing relevant phases of combustion, using a quartz-tube furnace coupled to a 
multistage cryotrap system (Kim et al., 2018). Organic extracts of each smoke condensate, which were assessed previously for lung toxicity and mutagenicity (Kim et al., 2018), were tested in a dose-dependent manner in a locomotor assay using 6-day post-fertilization zebrafish to assess irritant potential. It was postulated that fuel types that were resinous might result in combustion byproducts with the greatest irritant potential and that flaming combustion temperatures might, on an equal mass basis, further raise irritant potential given the elevated levels of known irritants, such as polycyclic aromatic hydrocarbons (PAHs) in flaming combustions. In addition, the potency extracts were compared on an emission factor (EF) basis, which reflects exposure based upon mass of fuel consumed. Finally, irritant responses were correlated to extract composition to determine the role of key chemical classes in driving toxicity. 


\section{CHAPTER 2: MATERIALS AND METHODS}

\section{Combustion and Byproduct Collection}

For this study, the fuel sources consisted of red oak (Quercus rubra), pocosin peat, ponderosa pine needles (Pinus ponderosa), lodgepole pine (Pinus contorta), and eucalyptus (Eucalyptus globulus), each representing fire-prone regions of the USA. Combustion of fuel sources and collection of condensates were described previously in greater detail (Kim et al., 2018). In brief, biomass combustion was carried out in a specialized furnace enabling tight control of combustion conditions. Each of the five fuel sources was burned, in separate efforts, at flaming $\left(640^{\circ} \mathrm{C}\right)$ and smoldering $\left(500^{\circ} \mathrm{C}\right)$ temperatures, generating 10 unique smoke profiles. Smoke from each burn was passed through a multi-phase cooling cryotrap system through 3 steps: $-10^{\circ} \mathrm{C},-50^{\circ} \mathrm{C}$, and $-70^{\circ} \mathrm{C}$. This system enabled collection of particulates, which may be difficult to remove from traditional filter-based systems, and volatile and semi-volatile combustion byproducts, which might not be collected using a filtration method. This method generated a condensate of smoke-derived particulates and semi-volatiles, which were then washed from the trap using acetone (Sigma-Aldrich; St. Louis, MO), concentrated using a nitrogen gas evaporation, and solvent exchanged into dimethyl sulfoxide (DMSO; $\geq 99.9 \%$ purity, Sigma-Aldrich; St. Louis, MO) creating a stock solution of 'extractable organic material' (EOM) that was stored at $4^{\circ} \mathrm{C}$ away from light.

\section{Chemicals}

Zebrafish embryos were reared in 10\% Hank's Buffered Saline Solution (HBSS); all salt components of which (13.7 mM NaCl, $0.54 \mathrm{mM} \mathrm{KCl}, 25 \mu \mathrm{M} \mathrm{Na} 2 \mathrm{HPO} 4,44 \mu \mathrm{M} \mathrm{KH} 2 \mathrm{PO} 4,130 \mu \mathrm{M}$ $\mathrm{CaCl} 2,100 \mu \mathrm{M}$ MgSO4, and $420 \mu \mathrm{M}$ NaHCO3; $\mathrm{pH}$ 7.6) were obtained from Sigma-Aldrich and 


\section{Experimental Animals}

Wild-type adult zebrafish (Danio rerio; undefined, outbred stock originally obtained from Aquatic Research Organisms, Hampton, NH, 03842 and EkkWill Waterlife Resources Ruskin, FL 33575) were housed in an Association for Assessment and Accreditation of Laboratory Animal Care-approved animal facility with a $14: 10 \mathrm{hr}$ light:dark cycle (lights on at 08:30 h). It was determined previously that behavioral responses in an outbred line of fish are like those in the $A B$ line of fish (unpublished data). Adult fish (males and females housed together, about 8/L) were kept in one of several 9-L colony tanks (Aquaneering Inc., San Diego, CA) with a water temperature of $28^{\circ} \mathrm{C}$. For group spawning, all adults from two different home tanks (80100 total fish) were placed in $15 \mathrm{~L}$ static tanks set up about 3:00 pm, with embryos collected the next morning between 8:30 and 9:00 am about 30 - 60 min after the light came on. All embryos were gathered from the breeder tank and placed in a $26^{\circ} \mathrm{C}$ water bath and washed twice (Westerfield, 2007) with $0.06 \%$ bleach (v/v) in 10\% HBSS for $5 \mathrm{~min}$. All studies were carried out in accordance with the guidelines of, and approved by, the Institutional Animal Care and Use Committee at the U.S. EPA's Center for Public Health and Environmental Assessment.

\section{Group Size Determinations and Controlling for Plate Variability}

Sample size analysis was performed using R Studio software (R Studio, Inc.) with the 'pwr' package (https://cran.r-project.org/web/packages/pwr/pwr.pdf) and 'pwr.anova.test' command and group sizes calculated based upon effect size indexes obtained from pilot studies. All experiments were performed over two plates with data combined from both plates to achieve the total ' $n$ ' for each group; this was done only after ensuring that there were no plate-to-plate differences.

\section{Concentration-Response Studies}

For the dose-response studies, zebrafish embryos were selected randomly from a plate containing hundreds of zebrafish embryos and then placed, one fish per well, into a 96 well plate ( 1 embryo/ well) on Day 0. At 6-days post-fertilization (dpf; $n=25$ to 32/experimental 
condition), larvae were exposed beginning approximately 8:00 AM to vehicle $(0.4 \%$ DMSO, final nominal concentration), or $0.3,0.96,3.0,9.6$ or $30 \mu \mathrm{g} E \mathrm{OM} / \mathrm{ml}$ and activity immediately assessed in the dark at $26^{\circ} \mathrm{C}$ for 60 min using Noldus (Leesburg, VA) Ethovision video tracking software (Figure 1). To achieve final concentrations, fresh stock plates containing concentrations 250X the final concentrations outlined in Figure 1 (i.e., 0, 0.3, 3.0, 10, and 30 $\mu \mathrm{g} / \mathrm{ml}$ ) were prepared. Then 1 microliter of stock solution was added to 249 microliters of HBSS in each well using a multi-channel pipette with dosing by row. These concentrations were in part based on concentrations used in our previous study (Stevens et al. 2018). In Stevens et al. 2018, the maximum concentration of $40 \mu \mathrm{g} / \mathrm{ml}$ elicited very potent irritating effects. To lessen the potential for overt toxicity a maximum concentration of $30 \mu \mathrm{g} / \mathrm{ml}$ was used in the present study. To incorporate as wide a concentration range as possible, doses were decreased by a half-log until the lowest dose $(0.3 \mu \mathrm{g} / \mathrm{ml})$ was achieved. At the end of the experiment, the embryos were anesthetized by immersion in ice-cold water. After the heartbeat had ceased, and the animals were unresponsive, the fish were euthanized by immersion in ice cold, $20 \%$ bleach (v/v) solution.

To compare potency of the EOM samples, linear regressions of the first 20 min of concentration-response data, which reflected the linear portion of the concentration-response curves for most extracts, were performed to determine slopes. The slopes of the linear regressions were used to indicate the toxicity potency of each extract. This mirrors a similar approach used previously to assess the potency of whole and fractionated diesel exhaust extracts (Stevens et al., 2018) and to quantify the mutagenic potencies of the PM extracts (Mutlu et al., 2013). Slopes were selected based upon the following criteria: 1) correlations that provided the highest goodness of fit (i.e., r-square value) and 2) the highest concentration before the concentration curve plateaued. 


\section{Behavioral Testing}

All testing was performed on 6 dpf larvae in 96-well plates (Figure 1). Video recording of larvae behavior was described previously (Stevens et al., 2018). On the morning of testing, after the rearing solution was changed, plates were moved to the dark in the behavioral testing room for $1 \mathrm{~h}$. Temperature in the testing room was kept at $26^{\circ} \mathrm{C}$. For testing, the plate was transferred to the light box in the testing apparatus for $25 \mathrm{~min}$, with dosing taking place during the last $5 \mathrm{~min}$ of the light program. Because irritant effects of exposure were of interest and organisms often adapt to irritant responses over time, the dark program was started immediately after dosing using a behavior-recording system (Media Recorder) to record immediate irritantinduced movement of each fish for $60 \mathrm{~min}$ in response to treatment.

Analysis of embryonic movement (locomotion) was tracked from videos using Ethovision XT (Noldus Information Technology) software Version 13 by an individual blinded to the treatment groups. Tracking rate was 5 samples/s (i.e., an image was captured every $200 \mathrm{msec}$ ). A dynamic subtraction method was used to detect objects that were darker than background, with a minimum object size of 10 pixels. Tracks were analyzed for total distance moved $(\mathrm{cm})$. The software provides a distance output per 2 min period. An input filter of $0.135 \mathrm{~cm}$ (minimum distance moved) was employed to remove system noise. All locomotion data were expressed as distance moved (cm) per unit time (Figure 1). 


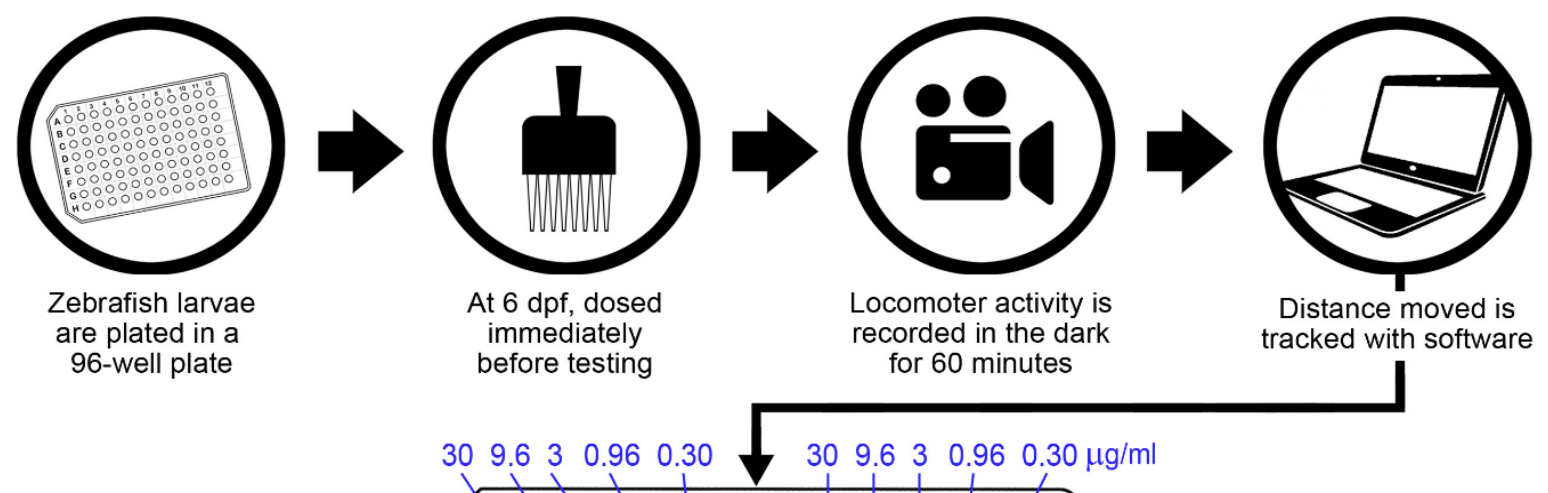

Control GOOOOOOOOOOOOO

untreated fish
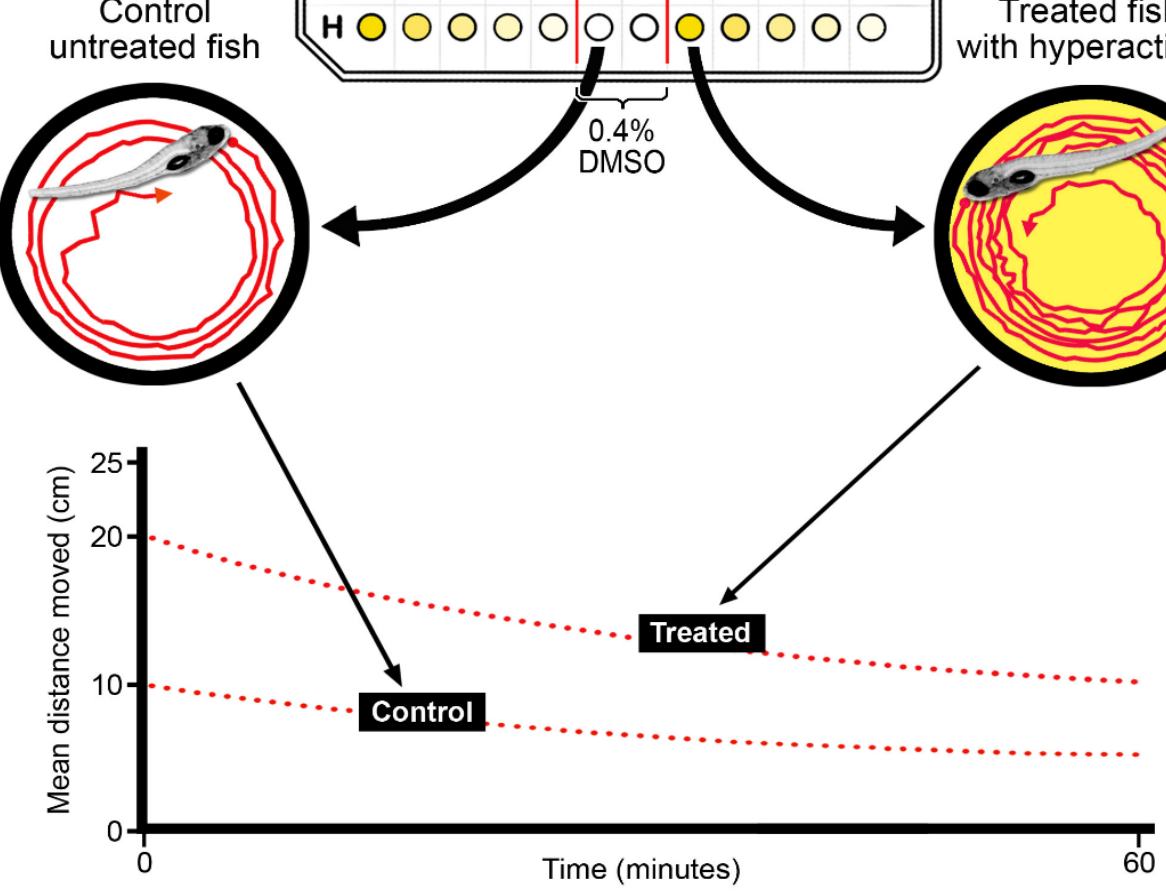

Figure 1. Experimental protocol for treatment and behavior assessment of zebrafish larvae. Zebrafish were plated at 6-8 $\mathrm{hr}$ postfertilization, and then dosed at 6-days postfertilization (dpf) with 0.3 to $30 \mu \mathrm{g} / \mathrm{ml}$ extractable organic material (EOM), immediately before assessment. Locomotor activity was recorded in the dark for $60 \mathrm{~min}$, and analysis software was used to derive distance moved $(\mathrm{cm}) /$ unit time ( $\mathrm{min}$ ). Control (unshaded wells) and treated (shaded wells) larvae were dosed in alternating columns of each 96-well plate. 


\section{Correlations of Potency vs. Chemical Constituents}

Linear regression was utilized to correlate potency both on a mass basis and an emission factor (EF) basis to some of the most prominent chemical classes including PAHs, organic carbon, methoxyphenols, and levoglucosan, the latter two chemicals of which are tracers of biomass burning in the atmosphere. The measurement of these chemicals was described previously (Kim et al. 2018). Tables 1 and 2 demonstrate the chemical concentrations on a mass or an EF basis, respectively.

Table 1: Concentrations of chemicals in the biomass smoke condensates in $\mathrm{mg} / \mathrm{g} \mathrm{PM}$

\begin{tabular}{|c|c|c|c|c|c|c|c|c|c|c|}
\hline & & & Smoldering & & & & & Flaming & & \\
\hline & $\begin{array}{c}\text { Pine } \\
\text { Needle }\end{array}$ & Red Oak & Pine Chips & Eucalyptus & Peat & $\begin{array}{c}\text { Pine } \\
\text { Needle }\end{array}$ & $\begin{array}{l}\text { Red } \\
\text { Oak }\end{array}$ & Pine Chips & Eucalyptus & Peat \\
\hline Methoxyphenols & 15301.78 & 31068.14 & 64976.87 & 21685.34 & 11613.96 & 3671.59 & 1195 & 15576 & 14909.52 & 475 \\
\hline Levoglucosan & 17296.21 & 78877.05 & 46366.29 & 52749.74 & 40957.26 & 14236.16 & 37300 & 61896 & 125828.57 & 8650 \\
\hline n-Alkanes & 736.08 & 33.81 & 69.07 & 673.82 & 9289.174 & 44.54 & 3410 & 1804 & 780.95 & 2714.29 \\
\hline PAHs & 2488.86 & 85.04 & 492.40 & 95.29 & 643.16 & 104.90 & 220 & 5280 & 5138.10 & 139.29 \\
\hline Steranes & 0 & 0 & 0 & 0 & 0 & 0 & 0 & 0 & 0 & 67.86 \\
\hline Hopanes & 0 & 0 & 0 & 0 & 185.8974 & 0 & 0 & 0 & 0 & 0 \\
\hline$O C$ & 699443 & 529508 & 601394 & 532723 & 797863 & 416413 & 629242 & 513893 & 624508 & 430830 \\
\hline
\end{tabular}

Adapted from Kim et al. 2018. EOM - extractable organic material; PAHs - polyaromatic hydrocarbons, OC organic carbon

Table 2: Concentrations of chemicals in the biomass smoke condensates in $\mathrm{g} / \mathrm{kg}$ fuel

\begin{tabular}{r|rrrrrrrrrr}
\multicolumn{1}{c}{ Smoldering } & \multicolumn{10}{c}{ Flaming } \\
\hline & Pine Needle & Red Oak & Pine Chips & Eucalyptus & Peat & Pine Needle & Red Oak & $\begin{array}{c}\text { Pine } \\
\text { Chips }\end{array}$ & Eucalyptus & Peat \\
Methoxyphenols & 1496.06 & 4075.83 & 9265.05 & 3469.22 & 825.52 & 3.82 & 1.25 & 15.58 & 14.76 & 0.57 \\
Levoglucosan & 1691.05 & 10347.88 & 6611.37 & 8438.90 & 2911.24 & 14.81 & 39.17 & 61.90 & 124.57 & 10.29 \\
n-Alkanes & 71.97 & 4.44 & 9.85 & 107.80 & 660.27 & 0.05 & 3.58 & 1.80 & 0.77 & 3.23 \\
PAHs & 243.34 & 11.16 & 70.21 & 15.24 & 45.72 & 0.11 & 0.23 & 5.28 & 5.09 & 0.17 \\
Steranes & 0.00 & 0.00 & 0.00 & 0.00 & 0.00 & 0.00 & 0.00 & 0.00 & 0.00 & 0.08 \\
Hopanes & 0.00 & 0.00 & 0.00 & 0.00 & 13.21 & 0.00 & 0.00 & 0.00 & 0.00 & 0.00 \\
OC & 68384.54 & 69466.15 & 85752.77 & 85225.03 & 56712.10 & 433.07 & 660.70 & 513.89 & 618.26 & 512.69 \\
MCE & 73 & 98.6 & 71 & 98 & 76 & 97 & 83.5 & 98.1 & 63 & 98
\end{tabular}

Adapted from Kim et al. 2018. EOM - extractable organic material; PAHs - polyaromatic hydrocarbons, OC organic carbon; MCE-modified combustion efficiency 


\section{Statistics}

All statistical analyses were performed using GraphPad Prizm Software Version 6.0 (La Jolla, CA). Normality of data distributions was assessed with normality tests (D'AgostinoPearson omnibus normality test) with significance set at $p<0.05$. The concentration vs. time data over the 60 min monitoring period reported in Figures 2 and 3 were not normally distributed and, therefore, were tested at each 2-min interval using the nonparametric Kruskal-Wallis test with Dunn's multiple comparisons post-test. A p value $<0.05$ was considered statistically significant. For a comparison of the potency (i.e., slope) data in Figures 4 and 5 , slopes were derived from the linear regression of the concentration-response curve during the first 20 min for each EOM sample. The slopes were compared via one-way ANOVA followed by Tukey's posthoc test. For this analysis, the slopes were entered as the mean, the standard error for the slope derived from the linear regression data, was entered as the standard error of the mean, and the degrees of freedom (df) value +1 was entered as " $n$ " or group size - the $d f$ for all groups in this analysis was 1 . To determine correlations between potency and chemical class reported in Figures 6 and 7, linear regressions were carried out to generate $r^{2}$ values and to determine if the slopes were significantly non-zero (i.e., $p<0.05$ ). The number of independent observations is provided in the figure legends. 


\section{CHAPTER 3: RESULTS}

\section{Time Course of Locomotor Responses to Extracts}

There were no major signs of overt toxicity (i.e., morphological change and/or absence of heartbeat) with treatment with any of the biomass EOM samples. There were only two instances of lethality on two separate plates (1 embryo out of 96 total embryo/plate). In addition, only 10 total fish spread out over 5 plates were abnormal or injured during handling. All nonsurviving, abnormal and injured fish were excluded from analysis. Treatment of zebrafish larvae with each of the five smoldering EOM samples induced concentration-dependent responses over time that were significantly greater than DMSO control for most of the monitoring period (Figure 2). 

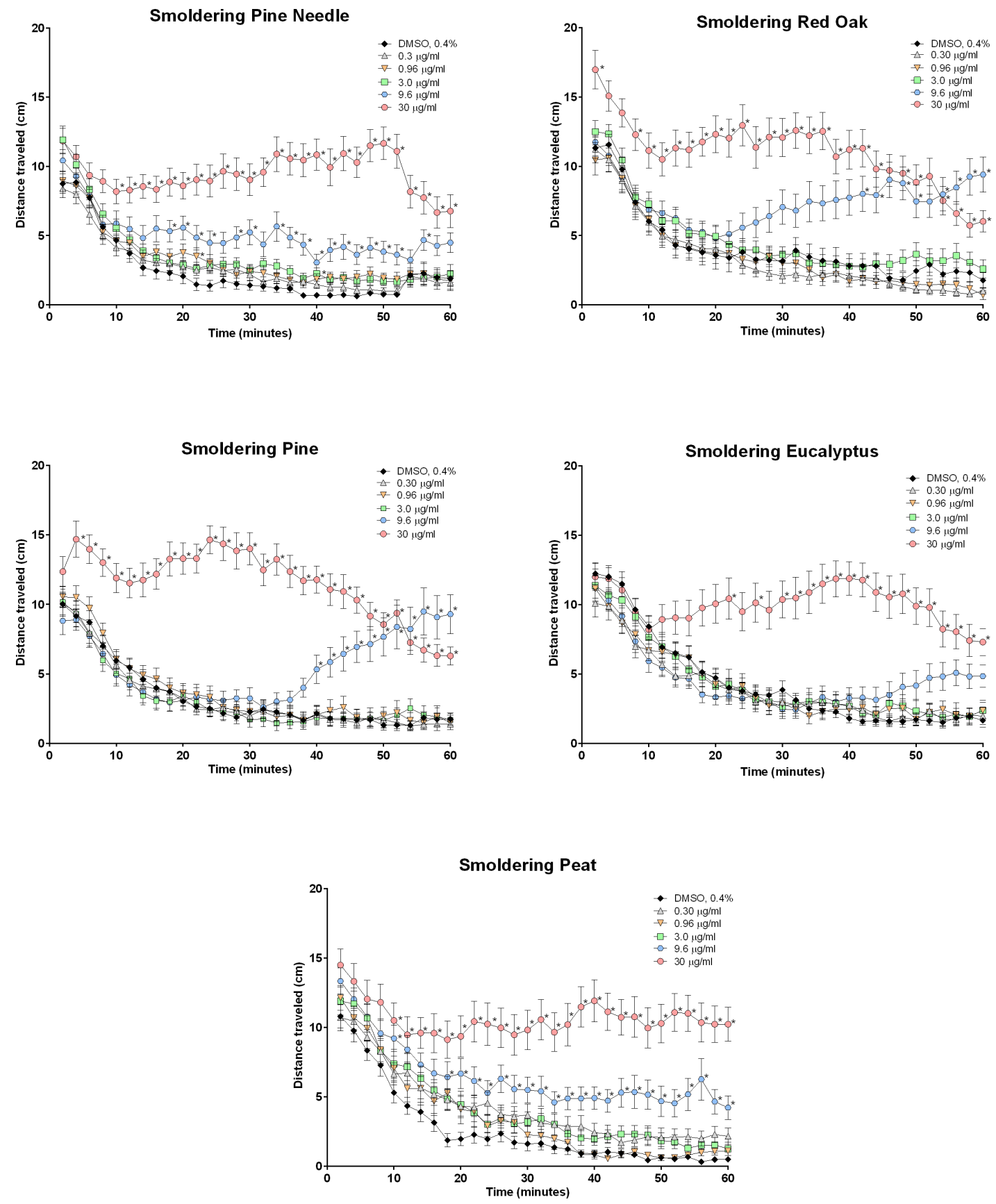

Figure 2: Effect of smoldering EOM samples on zebrafish larval locomotor activity measured in the dark over the course of a 60 -min monitoring period. Zebrafish were exposed to 0.3 to 30 $\mu \mathrm{g} / \mathrm{ml}$ EOM samples in $0.4 \%$ DMSO or $0.4 \%$ DMSO alone approximately 5 min before monitoring locomotor behavior. Data are presented as mean \pm SEM at each 2-min interval for the entire $60 \mathrm{~min}$ of recording. Data from 2 replicate plates were combined for a total of 25-32 zebrafish larvae per exposure group. *Significantly different from DMSO at corresponding time $(p<0.05)$. 
Exposure to the highest concentration of $30 \mu \mathrm{g} \mathrm{EOM} / \mathrm{ml}$ smoldering red oak and pine produced immediate significant increases over control, whereas significant responses with the remaining smoldering extracts at this concentration did not occur until 10 to 20 min into the monitoring period. All smoldering EOM samples except for eucalyptus initiated significant responses at the second highest concentration of $9.6 \mu \mathrm{g} \mathrm{EOM} / \mathrm{ml}$, although these responses at this concentration were delayed relative to the response at the highest treatment level.

Exposure of zebrafish larvae with each of the five flaming EOM samples also induced concentration-dependent responses over time that were significantly greater than control for most of the monitoring period (Figure 3). 

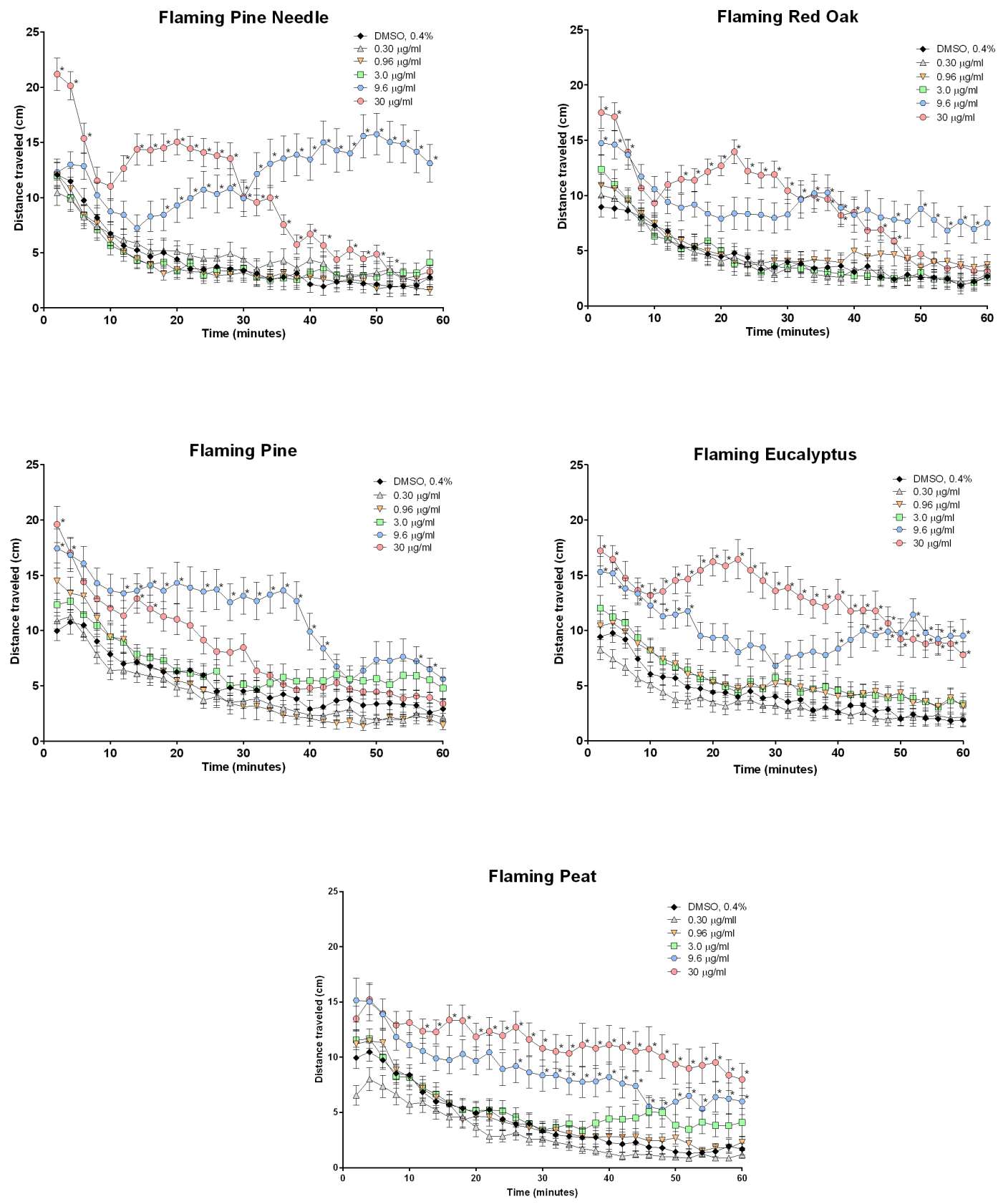

Figure 3: Effect of flaming EOM samples on zebrafish larval locomotor activity measured in the dark over the course of a 60 -min monitoring period. Zebrafish were exposed to 0.3 to $30 \square \mathrm{g} / \mathrm{ml}$ EOM samples in $0.4 \%$ DMSO or $0.4 \%$ DMSO alone approximately 5 min before monitoring locomotor behavior. Data are presented as mean \pm SEM at each 2 min interval for the entire 60 min of recordings. Data from 2 replicate plates were combined for a total of 25-32 zebrafish larvae per exposure group. *Significantly different from DMSO at corresponding time $(p<0.05)$. 
In contrast to the responses to smoldering EOM samples, the responses to the highest concentration (30 $\mu \mathrm{g} \mathrm{EOM} / \mathrm{ml})$ of all flaming EOM samples except peat were immediate and significantly greater than DMSO. The magnitude of the immediate differences in locomotor activity between control and the highest concentration for these flaming EOM samples was also greater than the respective differences with smoldering EOM samples, particularly with flaming pine needle. It is of interest that unlike responses to the smoldering EOM samples, the second highest concentration $(9.6 \mu \mathrm{g} / \mathrm{ml})$ of flaming red oak, pine and eucalyptus produced immediate significant elevation in locomotor activity relative to control, Further, the responses to the highest concentration of flaming pine needle, red oak, and pine, although significantly greater than control in the early part of the monitoring period, were no longer significant compared to control by the end of the monitoring period. These same EOM samples at the second highest concentration, however, remained significantly greater than control at the end of the monitoring period. It is important to note that only animals that had confirmed beating hearts were included in these assessments.

\section{Potency Determinations for Extracts}

Linear regressions were performed on data from the first 20 min of the concentrationresponse values because this was the period of the greatest increase in activity for most EOM samples. Linear regressions for all 10 EOM samples on an EOM mass basis (Figure 4) illustrated that the potencies (i.e., slopes) varied considerably. 


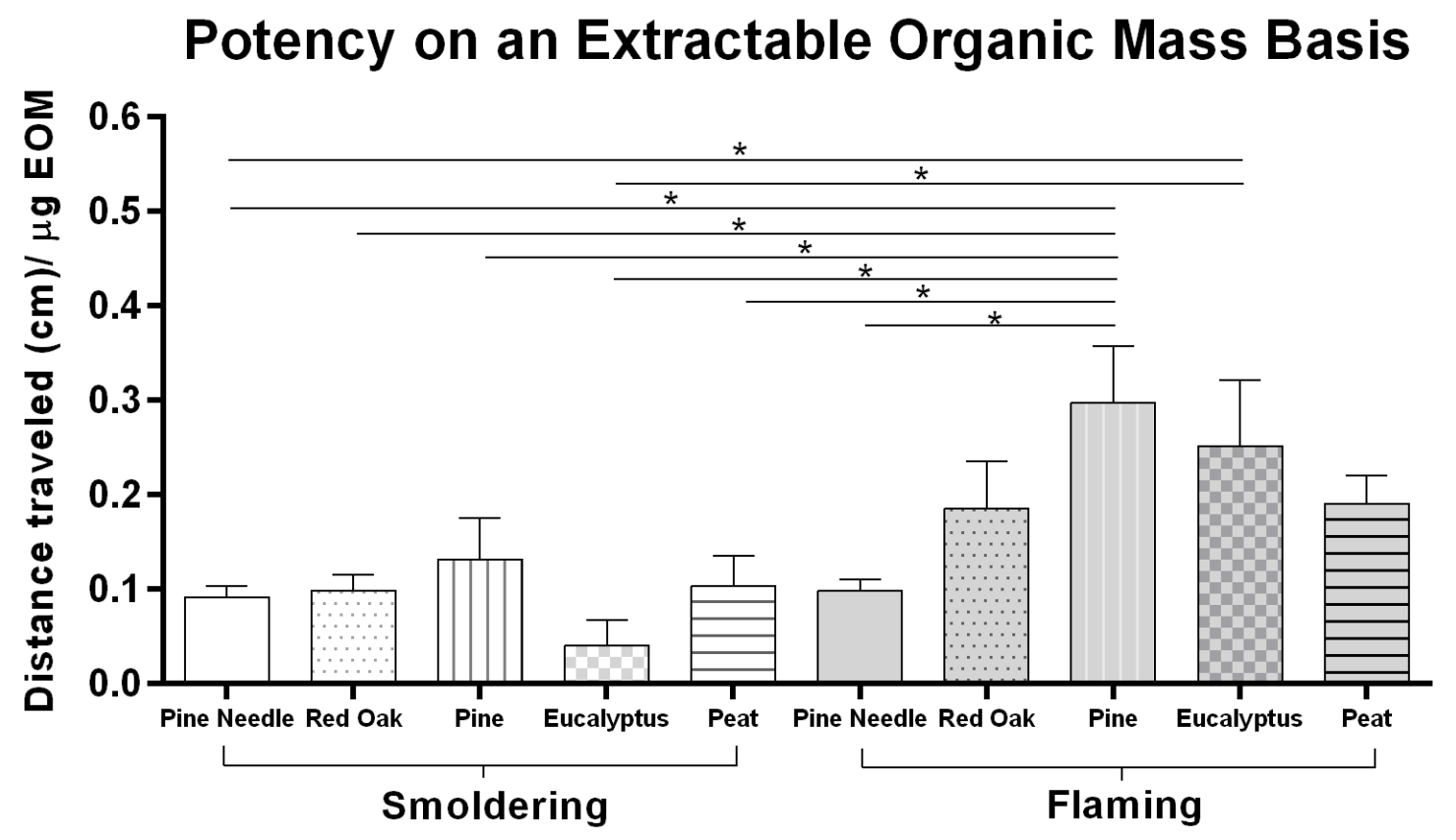

Figure 4: Potency of all extracts on an extractable organic material (EOM) basis in the zebrafish locomotor assay. The potency data are slopes of linear regressions of dose-response data for each extract. Data represent means standard error of the mean $(n=2)$. *Significant difference between indicated groups $(p<0.05)$.

Although there were no marked differences among the smoldering samples, smoldering eucalyptus was the least potent ranging from 2.25- to 3.23-fold lower than the remaining smoldering samples. Except for flaming pine needle, the flaming samples were more potent than the smoldering samples on an EOM mass basis. Flaming pine was the most potent sample with significantly greater potency than all smoldering samples and flaming pine with fold differences ranging from 2.27 (vs. smoldering pine) to 7.33 (vs. smoldering eucalyptus). Flaming eucalyptus was the next most potent flaming sample with markedly greater potency than smoldering pine and smoldering eucalyptus with respective fold differences of 2.74 and 6.2.

In contrast to the potencies on an EOM mass basis, linear regressions for all $10 \mathrm{EOM}$ samples (i.e., smoldering and flaming) on an emission factor basis (Figure 5), which accounts 
for the amount of PM produced per kg fuel, showed that the potencies for smoldering samples were greater than the potencies for the flaming samples. Smoldering pine, the most potent smoldering sample, was 185 -fold more potent on an emission factor basis than flaming pine needle, the least potent flaming sample. Smoldering pine was more potent than all the flaming samples as well as smoldering eucalyptus and smoldering peat. Smoldering red oak was also more potent than all the flaming samples.

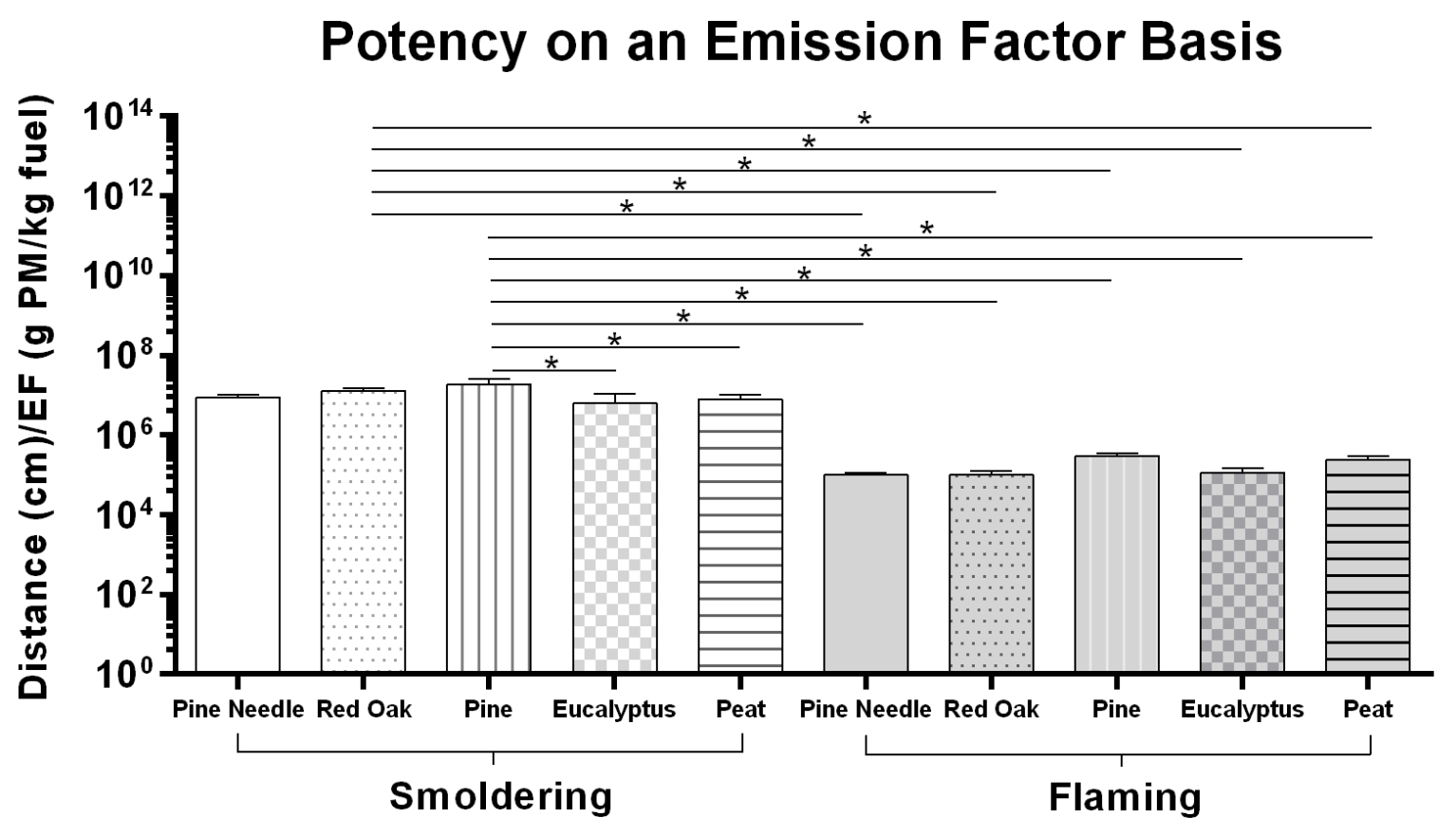

Figure 5: Potency of all extracts on an emission factor (EF) basis in the zebrafish locomotor assay. The potency data are slopes of linear regressions of dose-response data for each extract. Data represent means with standard error of the mean $(n=2)$. *Significant difference between indicated groups $(p<0.05)$.

\section{Correlations of Potency with Chemical Constituents}

Linear regressions of potency vs. concentration of chemicals representative of chemical classes were carried out to determine if there was a relationship between potency and 
concentrations of specific chemical classes. On an EOM mass basis (Figure 6), there was a significant positive correlation between potencies and $\mathrm{PAH}$ concentrations in the samples $\left(\mathrm{r}^{2}=\right.$ 0.55). However, there were no significant correlations between potency and organic carbon, methoxyphenols, or levoglucosan.
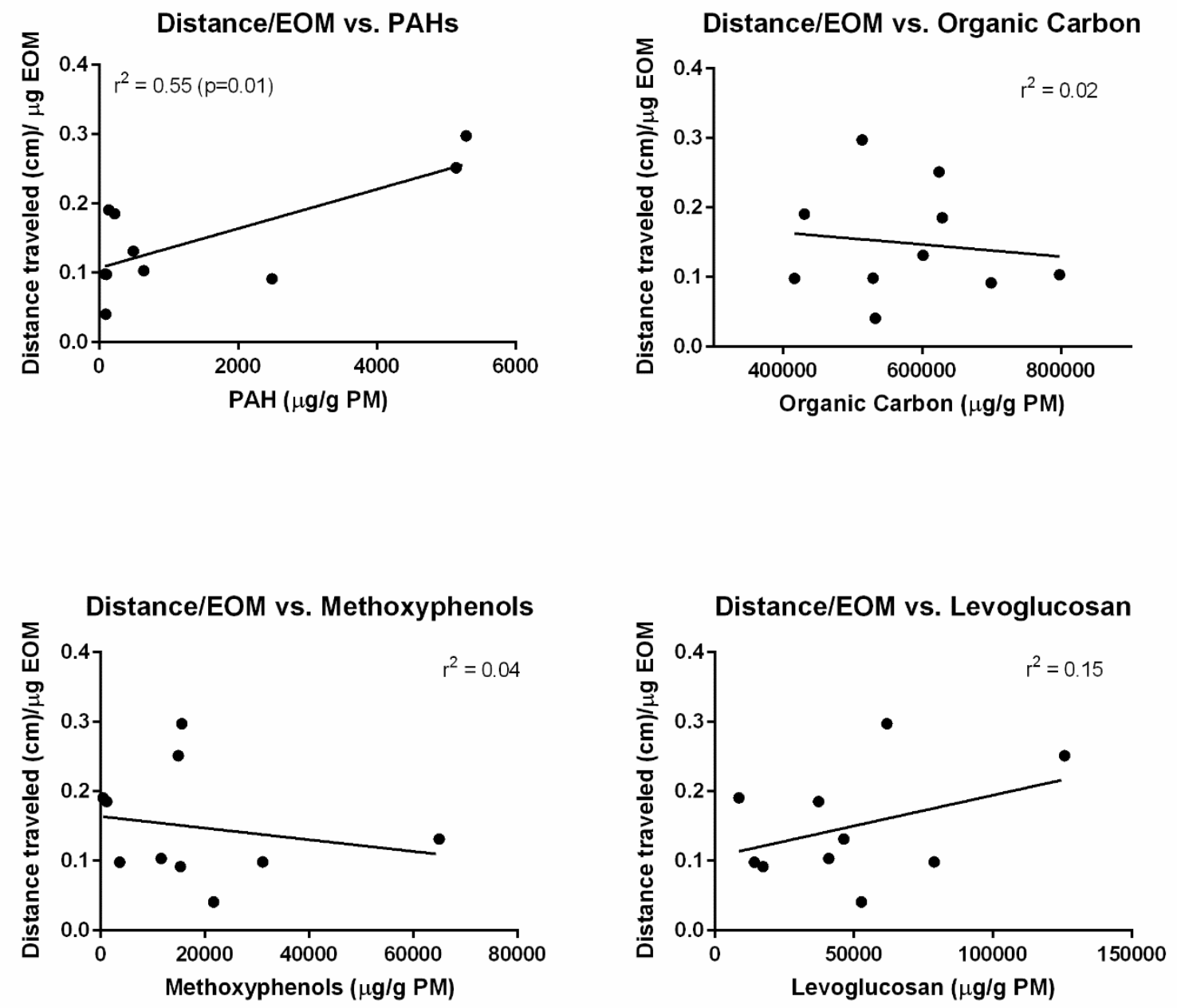

Figure 6: Correlations between irritant potencies in zebrafish and concentration of specific chemical classes on an extractable organic material (EOM) mass basis. Linear regression was used to correlate potency with concentrations of polyaromatic hydrocarbons (PAHs), organic carbon, methoxyphenols, and levoglucosan. $r^{2}-$ coefficient of determination. A $p<0.05$ indicates a significant non-zero slope. 
On an emission factor basis (Figure 7), there was an even stronger significant correlation between potency and PAH concentration $\left(r^{2}=0.91\right)$. There were no marked correlations between potency and organic carbon, methoxyphenols, or levoglucosan.

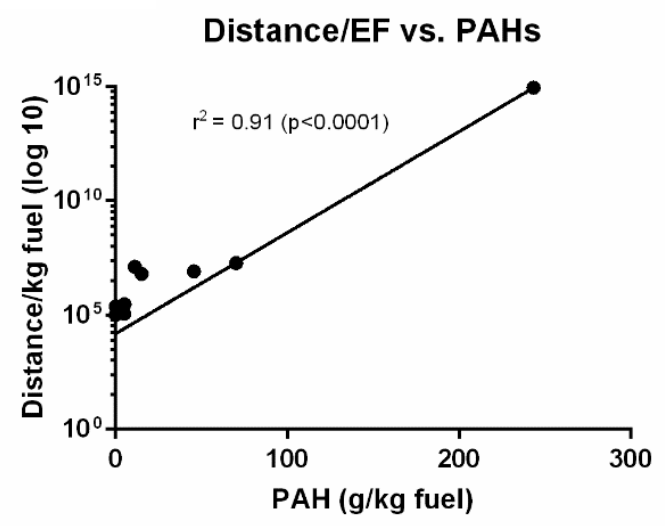

Distance/EF vs. Methoxyphenols

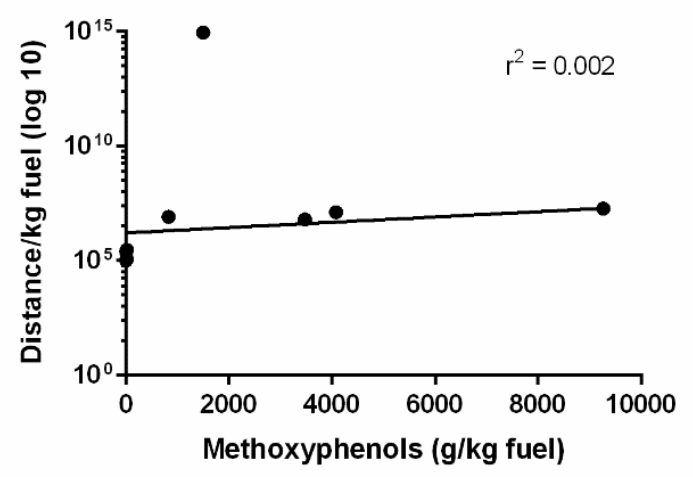

Distance/EF vs. Organic Carbon

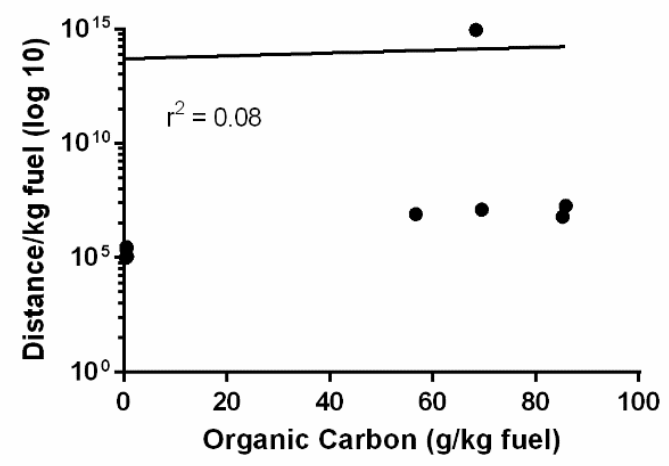

Distance/EF vs. Levoglucosan

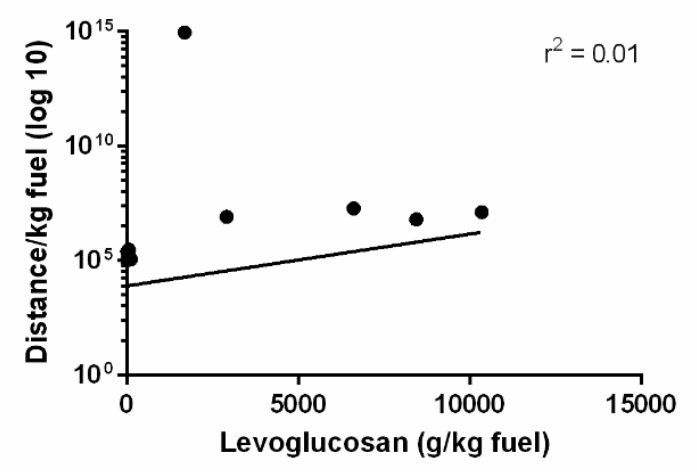

Figure 7: Correlations between irritant potencies in zebrafish and concentration of specific chemical classes on an emission factor (EF) basis. Linear regression was used to correlate potency with concentrations of polyaromatic hydrocarbons (PAHs), organic carbon, methoxyphenols, and levoglucosan. Note: nonlinear regression was used to generate a straight line. $r^{2}-$ coefficient of determination. A $p<0.05$ indicates a significant non-zero slope. 
All data (i.e., individual values used to generate means and standard deviations presented in the tables and figures reported in this manuscript) will be made available on the U.S. E.P.A. public data repository located at https://catalog.data.gov/harvest/epa-sciencehub 


\section{CHAPTER 4: DISCUSSION}

The present findings indicate that combustion byproducts from various biomass fuels elicit irritant locomotor responses in zebrafish, which may be similarly irritating to the respiratory tract of mammals. While other mechanisms can influence locomotor responses, the immediacy of the responses, which peaked soon after treatment, coupled with our previous findings that showed blockade of particulate-induced locomotor responses with TRPA1 inhibitors (Stevens et al. 2018), suggest strongly that irritant mechanisms are driving the responses to the biomass extracts in the present study. Extracts collected under flaming conditions initiated greater responses on an equal mass basis than extracts derived from smoldering burns, consistent with previous assessments of lung toxicity and mutagenicity to the same fuels (Kim et al., 2018; 2020). However, when expressed on an emission factor basis, smoldering combustion-derived extracts were more irritating than flaming-derived extracts, reflecting the fact that quantity of PM in the ambient air might constitute a major factor in the observed toxicity. Further, chemical composition appears to drive toxicity because irritant responses were strongly correlated with PAH concentration.

The organic extracts of all fuel types and burn conditions produced concentrationdependent hyperactive locomotor responses in zebrafish larvae that peaked during the first 20 min after exposure. These findings are consistent with our previous findings with organic extracts of petroleum diesel exhaust particulate matter (Stevens et al., 2018) and with welldocumented PM-induced respiratory irritant responses in humans (Xu et al., 2013) and rodents (Farraj et al., 2011; Filep et al., 2016; Kim et al., 2018; Sussan et al., 2014). Although decreasing only slightly during the first minutes after exposure, locomotor responses to the 
highest concentration of all smoldering extracts plateaued, remaining high persistently for the duration of the monitoring period relative to vehicle control, consistent with altered breathing responses of inhaled smoldering emissions reported in a rodent model (Hargrove et al., 2019). In contrast, flaming extracts elicited greater locomotor responses soon after exposure compared to smoldering extracts, although the responses to the highest concentration of some flaming extracts declined markedly to control levels before the end of the monitoring period likely due to induction of overt toxicity. This phenomenon is supported further by the fact that responses to the second highest concentration $(9.6 \mu \mathrm{g} \mathrm{EOM} / \mathrm{ml})$ of these same extracts was greater than both the high concentration and the control by the end of the monitoring period. Interestingly, among some extracts across both fuel types, there were two types of responses: an early peak with the high concentration and a delayed rise with the second highest amount. The reasons for this are unclear but may be related to the potential initiation of disparate mechanisms, one that triggered immediate irritant responses resulting from interaction of chemical constituents with zebrafish skin surface and a second delayed response that occurred due to internalization of such constituents over time.

Potency determinations derived from concentration-response data from all extracts revealed that fuel type and burn condition markedly influenced the magnitude of irritant responses. On an equal mass basis, the smoldering extracts did not vary in potency from one another. In contrast, among the flaming extracts, flaming pine and eucalyptus were the most potent, consistent with rodent studies that linked emissions from resinous samples with pulmonary inflammation (Kim et al., 2018). Further, on an equal mass basis, except for flaming pine, the flaming extracts were more potent than smoldering extracts of the same fuel type. The greater activity of the flaming samples on an equal mass basis might be attributed to higher $\mathrm{PAH}$ levels, which increase in wood smoke as combustion temperatures rise (McMohan and Tsoukalas, 1987; Bølling et al., 2012; Mcdonald et al., 2000). However, comparisons of potency on an equal mass basis do not account for the fact that smoldering burns generate greater 
quantity of $\mathrm{PM}_{2.5}$ than the flaming phase of combustion per mass of fuel burned. When comparing potency on an emission factor basis, which factors in the total amount of $\mathrm{PM}_{2.5}$ produced per $\mathrm{kg}$ fuel, the smoldering samples were greater than 2 orders of magnitude more potent than the flaming extracts of the same fuel type. Further, among smoldering extracts, pine on an emission factor basis was more potent than eucalyptus and peat, again demonstrating the enhanced relative toxicity of resinous fuels. Interestingly, eucalyptus extracts were the least potent of the fuel types when collected from smoldering burns but were among the most potent when collected after flaming combustion, indicating that combustion phase influences the relative toxicity of a given biomass.

The differences in potency among fuel types appear to be driven by chemical composition of the combustion-derived extracts. Potency on an equal mass basis was correlated positively with $\mathrm{PAH}$ concentration in a significant manner. This relationship was even stronger when potency was expressed on an emission factor basis. PAHs have been linked to PM-induced cytotoxicity, inflammation, and oxidative stress, among other mechanisms (Liu et al., 2017; Baulig et al., 2003). Oxidative stress and inflammation by PM constituents may trigger activation of the transient receptor potential ankyrin 1 (TRPA1) cation channels, which, Stevens et al (2018) noted previously, mediates irritant locomotor effects of organic constituents of diesel PM in zebrafish. Further, TRPA1 channels are expressed on the skin surface of larval zebrafish and similar to their mammalian orthologues, mediate chemo-sensation (Kroll et al., 2021; Prober et al., 2008). Red oak and eucalyptus are also rich in other semi-volatile organic compounds such as methoxyphenols (Kim et al., 2018). However, irritant potency did not correlate significantly with methoxyphenols, or other constituents including organic carbon and the semi-volatile levoglucosan. However, these data do not preclude involvement of other constituents such as heavy metals, which are present in varying quantities in biomass smoke (Kim et al. 2018). 
Although the present study examined locomotor responses, it is unclear to what extent such responses resulted from irritant effects triggered by sensory mechanisms at the skin surface and/or responses resulting from internalization of extract components. This study is therefore limited by the absence of measures of internal concentration, given that hydrophobic chemicals such as PAHs, which are abundant in various sources of PM, are readily absorbed by zebrafish (Kühnert et al., 2013), and once internalized may trigger inflammatory responses (Bai and Van Eeden, 2013). Further, while this model is useful in establishing the relative toxicity and biological potency of one PM source to another, the method of exposure, i.e., immersion, in this zebrafish model, precludes direct comparison with inhaled doses encountered by humans. The concentrations used, however, are comparable with PM exposure concentrations used in published in vitro human lung cell studies (Lyu et al., 2018; Niu et al., 2021:). Moreover, the biologically conserved sensory mechanisms and responsiveness to chemicals among zebrafish skin and mammalian lung epithelium suggest that the interaction of particulates with skin epithelium in this zebrafish model may be comparable and predictive of the irritant responses resulting from the interaction of inhaled particles with mammalian lung epithelium. Although smoldering and flaming extracts were examined separately in the present study, future investigations need to assess emissions resulting from concurrent flaming and smoldering burns because, in nature, both phases of biomass combustion occur together frequently.

These results demonstrate that the zebrafish locomotor assay is a useful tool for screening the irritant potential of biomass combustion emissions and may help expedite relative toxicity determinations of various wildland fire-related sources. Stratification of biomass fuel type and associated combustion conditions based on biological potency in this model system may help guide targeted inhalation exposure studies in higher order mammalian models. 


\section{REFERENCES}

Bai, N. and Van Eeden, S.F. 2013. Systemic and vascular effects of circulating diesel exhaust particulate matter. Inhal. Toxicol. 25:725-734.

Baulig, A., Garlatti, M., Bonvallot, V., Marchand, A., Barouki, R., Marano, F., \& Baeza-Squiban, A. 2003. Involvement of reactive oxygen species in the metabolic pathways triggered by diesel exhaust particles in human airway epithelial cells. Am. J. Physiol. - Lung Cell. Mol. Physiol. 285:L671-L679.

Bølling, A. K., Totlandsdal, A. I., Sallsten, G., Braun, A., Westerholm, R., Bergvall, C., Boman, J., Dahlman, H. J., Sehlstedt, M., Cassee, F., Sandstrom, T., Schwarze, P. E., \& Herseth, J. I. 2012. Wood smoke particles from different combustion phases induce similar proinflammatory effects in a co-culture of monocyte and pneumocyte cell lines. Part. Fibre Toxicol. 9:1-15.

Burke, M., Driscoll, A., Heft-Neal, S., Xue, J., Burney, J., \& Wara, M. 2019. The Changing Risk and Burden of Wildfire in the U.S. NBER Work. Pap. 118:1-6.

Cochard, M., Ledoux, F., \& Landkocz, Y. 2020. Atmospheric fine particulate matter and epithelial mesenchymal transition in pulmonary cells: state of the art and critical review of the in vitro studies. Journal of toxicology and environmental health. Part $B$, Critical reviews, 23(7), 293-318.

Farraj, A. K., Haykal-Coates, N., Winsett, D. W., Gilmour, M. I., King, C., Krantz, Q. T., Richards, J., \& Hazari, M. S. 2015. Comparative electrocardiographic, autonomic and systemic inflammatory responses to soy biodiesel and petroleum diesel emissions in rats. Inhal. Toxicol. 27:564-575.

Farraj, A. K., Hazari, M. S., Haykal-Coates, N., Lamb, C., Winsett, D. W., Ge, Y., Ledbetter, A. D., Carll, A. P., Bruno, M., Ghio, A., \& Costa, D. L. 2011. ST depression, arrhythmia, vagal dominance, and reduced cardiac micro-RNA in particulate-exposed rats. Am. J. Respir. Cell Mol. Biol. 44:185-196.

Filep, Á., Fodor, G. H., Kun-Szabó, F., Tiszlavicz, L., Rázga, Z., Bozsó, G., Bozóki, Z., Szabó, G., \& Peták, F. 2016. Exposure to urban PM1 in rats: Development of bronchial inflammation and airway hyperresponsiveness. Respir. Res. 17: 1-11.

Gavett, S. H., Wood, C. E., Williams, M. A., Cyphert, J. M., Boykin, E. H., Daniels, M. J., Copeland, L. B., King, C., Krantz, T. Q., Richards, J. H., Andrews, D. L., Jaskot, R. H., \& Gilmour, M. I. 2015. Soy biodiesel emissions have reduced inflammatory effects compared to diesel emissions in healthy and allergic mice. Inhal. Toxicol. 27:533-544.

Gunnarsson, L., Jauhiainen, A., Kristiansson, E., Nerman, O., \& Larsson, D. G. 2008. Evolutionary conservation of human drug targets in organisms used for environmental risk assessments. Environmental Science \& Technology. 42(15):5807-5813.

Hargrove, M. M., Kim, Y. H., King, C., Wood, C. E., Gilmour, M. I., Dye, J. A., \& Gavett, S. H. 2019. Smoldering and flaming biomass wood smoke inhibit respiratory responses in mice. Inhal. Toxicol. 31: 236-247. 
Hazari, M. S., Haykal-Coates, N., Winsett, D. W., King, C., Krantz, Q. T., Gilmour, M. I., \& Farraj, A. K. 2015. The effects of B0, B20, and B100 soy biodiesel exhaust on aconitineinduced cardiac arrhythmia in spontaneously hypertensive rats. Inhal. Toxicol. 27:557-563.

Hime, N. J., Marks, G. B., \& Cowie, C. T. 2018. A comparison of the health effects of ambient particulate matter air pollution from five emission sources. Int. J. Environ. Res. Public Health. 15: 1-24.

H owe, K., Clark, M. D., Torroja, C. F., Torrance, J., Berthelot, C., Muffato, M., Collins, J. E., Humphray, S., McLaren, K., Matthews, L., McLaren, S., Sealy, I., Caccamo, M., Churcher, C., Scott, C., Barrett, J. C., Koch, R., Rauch, G. J., White, S., Chow, W., ... Stemple, D. L. 2014. The zebrafish reference genome sequence and its relationship to the human genome. Nature. 505(7482):248.

Jolly, W. M., Cochrane, M. A., Freeborn, P. H., Holden, Z. A., Brown, T. J., Williamson, G. J., \& Bowman, D. M. 2015. Climate-induced variations in global wildfire danger from 1979 to 2013. Nat. Commun. 6:1-11.

Kim, Y. H., King, C., Krantz, T., Hargrove, M. M., George, I. J., McGee, J., Copeland, L., Hays, M. D., Landis, M. S., Higuchi, M., Gavett, S. H., \& Gilmour, M. I. 2019. The role of fuel type and combustion phase on the toxicity of biomass smoke following inhalation exposure in mice. Archives of toxicology. 93(6):1501-1513.

Kim, Y. H., Warren, S. H., Krantz, Q. T., King, C., Jaskot, R., Preston, W. T., George, B. J., Hays, M. D., Landis, M. S., Higuchi, M., DeMarini, D. M., \& Gilmour, M. I. 2018. Mutagenicity and Lung Toxicity of Smoldering vs. Flaming Emissions from Various Biomass Fuels: Implications for Health Effects from Wildland Fires. Environ. Health Perspect. 126 (1).

Kroll, F., Powell, G. T., Ghosh, M., Gestri, G., Antinucci, P., Hearn, T. J., Tunbak, H., Lim, S., Dennis, H. W., Fernandez, J. M., Whitmore, D., Dreosti, E., Wilson, S. W., Hoffman, E. J., \& Rihel, J. 2021. A simple and effective F0 knockout method for rapid screening of behaviour and other complex phenotypes. eLife. 10:e59683.

Kühnert, A., Vogs, C., Altenburger, R., \& Küster, E. 2013. The internal concentration of organic substances in fish embryos-A toxicokinetic approach. Environ. Toxicol. Chem. 32: 18191827.

Lim, S. S., Vos, T., Flaxman, A. D., Danaei, G., Shibuya, K., Adair-Rohani, H., Amann, M., Anderson, H. R., Andrews, K. G., Aryee, M., Atkinson, C., Bacchus, L. J., Bahalim, A. N., Balakrishnan, K., Balmes, J., Barker-Collo, S., Baxter, A., Bell, M. L., Blore, J. D., Blyth, F., ... Memish, Z. A. 2012. A comparative risk assessment of burden of disease and injury attributable to 67 risk factors and risk factor clusters in 21 regions, 1990-2010: A systematic analysis for the Global Burden of Disease Study 2010. Lancet. 380: 2224-2260.

Liu, J. C., Wilson, A., Mickley, L. J., Dominici, F., Ebisu, K., Wang, Y., Sulprizio, M. P., Peng, R. D., Yue, X., Son, J. Y., Anderson, G. B., \& Bell, M. L. 2017. Wildfire-specific fine particulate matter and risk of hospital admissions in urban and rural counties. Epidemiology. 28: 7785.

Lyu, Y., Su, S., Wang, B., Zhu, X., Wang, X., Zeng, E. Y., Xing, B., \& Tao, S. 2018. Seasonal and spatial variations in the chemical components and the cellular effects of particulate 
matter collected in Northern China. The Science of the total environment., 627:1627-1637.

Martin, B. L., Thompson, L. C., Kim, Y. H., King, C., Snow, S., Schladweiler, M., Haykal-Coates, N., George, I., Gilmour, M. I., Kodavanti, U. P., Hazari, M. S., \& Farraj, A. K. 2020. Peat smoke inhalation alters blood pressure, baroreflex sensitivity, and cardiac arrhythmia risk in rats. Journal of toxicology and environmental health. Part A, 83(23-24): 748-763.

Mazzoleni, L. R., Zielinska, B., \& Moosmüller, H. 2007. Emissions of levoglucosan, methoxy phenols, and organic acids from prescribed burns, laboratory combustion of wildland fuels, and residential wood combustion. Environ. Sci. Technol. 41:2115-2122.

McMohan, C.K. and Tsoukalas, S.N. 1987. Polynuclear aromatic hydrocarbons in forest fire smoke. Carcinogenesis. 61-73.

Mutlu, E., Warren, S. H., Matthews, P. P., King, C., Linak, W. P., Kooter, I. M., Schmid, J. E., Ross, J. A., Gilmour, M. I., \& Demarini, D. M. 2013. Bioassay-directed fractionation and sub-fractionation for mutagenicity and chemical analysis of diesel exhaust particles. Environ. Mol. Mutagen. 54:719-736.

Mutlu, E., Warren, S. H., Matthews, P. P., Schmid, J. E., Kooter, I. M., Linak, W. P., lan Gilmour, M., \& DeMarini, D. M. 2015. Health effects of soy-biodiesel emissions: bioassay-directed fractionation for mutagenicity. Inhal. Toxicol. 27:597-612.

Niu, X., Jones, T., BéruBé, K., Chuang, H. C., Sun, J., \& Ho, K. F. 2021. The oxidative capacity of indoor source combustion derived particulate matter and resulting respiratory toxicity. The Science of the total environment: 767:144391.Park, M., Joo, H. S., Lee, K., Jang, M., Kim, S. D., Kim, I., Borlaza, L., Lim, H., Shin, H., Chung, K. H., Choi, Y. H., Park, S. G., Bae, M. S., Lee, J., Song, H., \& Park, K. 2018. Differential toxicities of fine particulate matters from various sources. Sci. Rep. 8:1-11.

Prober, D. A., Zimmerman, S., Myers, B. R., McDermott, B. M., Jr, Kim, S. H., Caron, S., Rihel, J., Solnica-Krezel, L., Julius, D., Hudspeth, A. J., \& Schier, A. F. 2008. Zebrafish TRPA1 channels are required for chemosensation but not for thermosensation or mechanosensory hair cell function. J. Neurosci. 28:10102-10110.

Samet, J. M., Rappold, A., Graff, D., Cascio, W. E., Berntsen, J. H., Huang, Y. C., Herbst, M., Bassett, M., Montilla, T., Hazucha, M. J., Bromberg, P. A., \& Devlin, R. B. 2009. Concentrated Ambient Ultrafine Particle Exposure Induces Cardiac Changes in Young Healthy Volunteers. Am. J. Respir. Crit. Care Med. 179.:1034-1042.

Shkirkova, K., Lamorie-Foote, K., Connor, M., Patel, A., Barisano, G., Baertsch, H., Liu, Q., Morgan, T. E., Sioutas, C., \& Mack, W. J. 2020. Effects of ambient particulate matter on vascular tissue: a review. Journal of toxicology and environmental health. Part $B$, Critical reviews, 23(7):319-350.

Stevens JS, Padilla S, DeMarini DM, Hunter DL, Martin WK, Thompson LC, Gilmour MI, Hazari MS, Farraj AK. 2018. Zebrafish locomotor responses reveal irritant effects of fine particulate matter extracts and a role for TRPA1. Toxicol. Sci. 161:290-299.

Sussan, T. E., Ingole, V., Kim, J. H., McCormick, S., Negherbon, J., Fallica, J., Akulian, J., Yarmus, L., Feller-Kopman, D., Wills-Karp, M., Horton, M. R., Breysse, P. N., Agrawal, A., 
Juvekar, S., Salvi, S., \& Biswal, S. 2014. Source of biomass cooking fuel determines pulmonary response to household air pollution. Am. J. Respir. Cell Mol. Biol. 50:538-548.

Trenberth, K.E. (2011) Changes in precipitation with climate change. Clim. Res., 47, 123-138.

Urbanski, SP. 2013. Combustion efficiency and emission factors for wildfire-season fires in mixed conifer forests of the northern Rocky Mountains, US. Atmos. Chem. Phys. 13:72417262.

Urbanski, S.P., Hao, W.M., Baker, S. 2009. Chapter 4 Chemical Composition of Wildland Fire Emissions. In: Bytnerowicz, A.; Arbaugh, M.; Riebau, A.; Andersen, C., eds. Developments in environmental science. Volume 8: Wildland fires and air pollution. The Netherlands: Elsevier: 79-107.

Wellenius, G. A., Saldiva, P. H., Batalha, J. R., Krishna Murthy, G. G., Coull, B. A., Verrier, R. L., \& Godleski, J. J. 2002. Electrocardiographic changes during exposure to residual oil fly ash (ROFA) particles in a rat model of myocardial infarction. Toxicol. Sci. 66:327-335.

Westerfield, M. 2007. The Zebrafish Book. A Guide for the Laboratory Use of Zebrafish (Danio rerio), 5th Edition. Univ. Oregon Press. Eugene.

Westerling, A. L., Hidalgo, H. G., Cayan, D. R., \& Swetnam, T. W. 2006. Warming and earlier spring increase Western U.S. forest wildfire activity. Science. 313:940-943.

Wettstein, Z. S., Hoshiko, S., Fahimi, J., Harrison, R. J., Cascio, W. E., \& Rappold, A. G. 2018. Cardiovascular and Cerebrovascular Emergency Department Visits Associated With Wildfire Smoke Exposure in California in 2015. J. Am. Heart Assoc. 7:e007492.

Xu, Y., Barregard, L., Nielsen, J., Gudmundsson, A., Wierzbicka, A., Axmon, A., Jönsson, B. A., Kåredal, M., \& Albin, M. 2013. Effects of diesel exposure on lung function and inflammation biomarkers from airway and peripheral blood of healthy volunteers in a chamber study. Part. Fibre Toxicol. 10:1-9. 